\title{
Supervisor Bottom-Line Mentality, Instrumentalism Ethical Climate and Employee's Unethical Behavior: The Moderate Effect of Moral Identity
}

\author{
Yijiu Ge \\ School of Business Administration \\ Zhejiang Gongshang University \\ Hangzhou 310000
}

\begin{abstract}
Based on social information processing theory, this study proved that supervisor bottom-line mentality positively influenced unethical behavior through instrumentalism ethical climate. Also, the moderating role of moral identity was examined. The study selected 319 pairs of sample data. We explored the relationship between the supervisor bottom-line mentality and employees' unethical behavior. The research results show that supervisor bottom-line mentality has a significant positive relationship with instrumentalism ethical climate (Hypothes is 1). Ins trumentalism ethical climate-mediated the relationship between leadership bottom-line mentality and unethical behavior (Hypothes is 2). Moral identity moderated the relationship between instrumentalism ethical climate and une thical (Hypothesis 3).
\end{abstract}

Keywords-Supervisor Bottom-line Mentality, Instrumentalism Ethical Climate, Unethical Behavior, Moral Identity

Recently, a numerous business ethical scandals have been exposed. The major cause to this phenomenon is these companies pursue to maximize the profit and ignore commercial ethics. It leads to tarnishing their public image and credit crisis and slows down the development of those companies. Therefore, people have started paying attention to unethical behavior in organizations and it becomes a hot topic for the academic and practice fields. Consistent with previous research, we have defined unethical behavior as the behavior that violates the widely accepted ethical norms ${ }^{[1]}$, such as falsifying bills, leaking company secrets, company assets, etc. ${ }^{[2]}$. The unethical behaviors in the organization have an impact on employees' individual performance and internal trust relationship, and even pose a great threat to organizational performance, inter-organizational relationship and network $[3,4,5,6]$. Therefore, it is of great significance to explore the generation mechanism of unethical behaviors and to prevent and control them.

The study found that supervisors have an extremely important influence on employees' behaviors and attitudes ${ }^{[7]}$. The supervisor's attitude and behavior are the important antecedent variables for the study of employees' unethical behaviors, such as ethical leadership ${ }^{[8]}$, transformational leadership ${ }^{[9]}$, etc. China is in a rapid development stage, in order to respond to the fierce market competition, the supervisor often only one-sided emphasis on the business results which can bring profits for enterprise, while ignoring the other notable things ${ }^{[10]}$ that is what we called Supervisor bottom-line mentality (BLM). At present, the concept of bottom line mentality has not been fully incorporated into the literature of organizational behavior, and it is not clear whether this attitude leads to the occurrence of bad behaviors ${ }^{[11]}$, such as employees' unethical behavior. Therefore, it is necessary to explore how the supervisor BLM affects employees' unethical behavior. Based on the social information processing theory, supervisor is considered to be the symbol of power and status. It is an important source for employees to search for information ${ }^{[12]}$, He has an important guiding role in the establishment of employees' work behavior and ethical standards, thus affecting the ethical climate in the organization. At the same time, the ethical climate tends to deal with organizational and personal moral issues in a subtle way. On the contrary, the negative ethical climate can easily cause employees' unethical behaviors ${ }^{[13]}$. However, from the point of view of individual moral characteristics, the different levels of employee moral identity have different ways of collecting and handling moral information in the organizational context. It shows that moral identity has a regulatory effect on employees' unethical behavior in a negative ethical climate.

First of all, based on the considerations above, combining with the social information processing theory, this study examines the supervisor BLM has certain predicative functions to instrumentalism ethical climate, and the mediating role of instrumentalism ethical climate in the supervisor BLM and unethical behavior. Secondly, the study suggests that moral identity can moderate the relationship between the instrumentalism ethical climate and unethical behavior. On the one hand, this study starts from the perspective of cognitive psychology to illustrate how the supervisor BLM forms instrumentalism ethical climate, thereby affecting unethical behaviors, and to expand the theoretical framework of unethical behavior with a new way. On the other hand, this study explores the effective control and prevention programs, and also has important management implications for reducing unethical behaviors of organization and employees. 


\section{TheORETICAL BACKGROUND AND HyPOTHESES}

\section{A. Supervisor Bottom-Line Mentality and Instrumentalism Ethical Climate}

Wolfe noted that the bottom line is often referred as financial consequences. Employees almost exclusively focus on a particular factor or consideration that is identified as being most important, while the importance of everything else is minimized ${ }^{[10]}$. For companies, securing certain bottom-line outcomes is normally considered beneficial to organizational profitability ${ }^{[14]}$. But to employees, it is often a prerequisite for employee rewards ${ }^{[15]}$. However, the concentration on the bottom line may become problematic when supervisor treat it as if it is the only objective to strive for ${ }^{[10]}$. The study shows that supervisor BLM can lead to employees in the form of social undermining deliberately impede the work of others and provide false information to mislead others to cause the task to fail ${ }^{[11]}$.

The ethical climate is essentially about the common recognition of ethical behaviors among the members of the organization. It mainly includes the judgment in the organization whether employees' behaviors conform to moral standards and the handling of unethical behaviors ${ }^{[16]}$. The instrumentalism ethical climate is a type of organizational ethical climate, which refers to the negative ethical atmosphere in which individuals ignore other factors when making decisions for the purpose of pursuing selfish interests. As mentioned above, the negative ethical climate may cause employees to ignore the moral norms and exercise unethical behavior. Therefore, the s instrumentalism ethical climate has received extensive attention from scholars in the study of unethical behavior ${ }^{[17]}$.

According to the social information processing theory, the individual cognitive judgment and behavior reaction will largely depend on the perimeter of the social information clue and then put forward the common perception derived from the social interaction between team members. It also emphasizes the social environment influence on employees' cognitive and behavioral ${ }^{[12]}$. That means employees will observe other members' attitude and behavior in the organization (e.g., supervisors and colleagues) and use this information to construct their own perceptions and values. Social influences serve as a catalyst for subordinates to develop and modify their beliefs and values. However, a supervisor can control subordinates' resources (e.g., salary, bonus, promotion, etc.), whose power and prestige in the organization is often higher. These contingencies of power force subordinates to attend to their supervisors' attitudes and behaviors and look to their supervisors for cues on organizational attitudinal and behavioral norms ${ }^{[19]}$. Additionally, supervisors are often deemed as credible role models within organizations ${ }^{[20]}$, which further adds to the likelihood that supervisors will gain their subordinates' attention. When supervisors have a baseline mindset, they send out cues to indicate that the bottom line is more important than any other factor ${ }^{[10]}$. They will support the bottom-line and use their power through rewards and punishments measures to strengthen the subordinate around the bottom line to arrange work. This will encourage employees to think about their work tasks simply and pursue the work results in a single way to gain their own interests and ignore the moral consequences ${ }^{11]}$. Therefore, employees' moral decisions and behaviors are adversely affected, which in turn encourages the instrumentalism ethical climate. On the basis of these arguments, we hypothesize the following:

Hypothesis 1: Supervisor BLM is positively related to instrumentalism ethical climate.

\section{B. Supervisor Bottom-Line Mentality, Instrumentalism Ethical Climate and Unethical Behavior}

Based on the social information processing theory, the information sent by the supervisor enables employees to perceive the organizational norms, belief and values ${ }^{[12]}$. Therefore, the supervisor BLM changes employees' working attitude. Employees around the bottom-line results, and view it as the only goal, in order to admitted by the supervisors, thereby obtaining more resources from the supervisors to ensure that he is high levels of competitiveness in the organization for their own further interests. From another perspective, these employees may be willing to take any action that will make them more likely to ensure the bottomline with little regard for other possible consequences. The supervisor BLM promotes the spread of egoism and also promotes the formation of instrumentalism ethical climate. In addition, the existing research shows that the organizational ethical climate is one of the important factors affecting employees' moral decision-making. In the instrumentalism ethical climate, individuals only pay attention to whether they can make profits in the organization, and ignore the negative impacts on others, even with some unjustified means to ensure their own interests to maximize ${ }^{[1,17,20]}$, which leads to the deterioration of the organizational ethical climate and induce the employees' unethical behaviors. In other words, the stronger the instrumentalism ethical climate in the organization, the more unethical behaviors exhibited by employees $^{[13]}$. Combining with hypothesis 1 , supervisor BLM will lead to the formation of instrumentalism ethical climate, thus promoting the generation of unethical behaviors. On the basis of these arguments, we hypothesize the following:

Hypothesis 2: Supervisor BLM will have a positive indirect effect on unethical behavior via instrumentalism ethical climate.

\section{The Moderating role of Moral Identity}

There are two different opinions of moral identity in the theoretical circle. They respectively put forward the moral identity of static stability ${ }^{[21]}$ and the moral identity of dynamic change ${ }^{[22]}$ respectively from the perspectives of trait theory and social cognition theory. Blasi believes that personal identification with morality is independent of external factors. While Aquino and Reed's views are based on social cognition theory. They believe that the strength of moral identity is affected by factors such as social environment, social information processing, and moral accessibility, and this view 
is accepted by most scholars. Aquino and Reed define moral identity as the part of the self-concept that is closely linked with moral characteristics. Specifically, moral identity can be divided into two dimensions: internalization and symbolization. The former reflects the importance of moral characteristics on self-concept, that is, the consistency of individual self-concept and moral characteristics. The later shows the degree of moral characteristics in daily life ${ }^{[22]}$. Previous studies have shown that moral identity influences individuals' control of moral or unethical behaviors through moral cognition ${ }^{[23]}$, and it can effectively constrain unethical behavior.

Moral identity is a key psychological mechanism that transforms moral cognition into moral behavior. It is a key factor in maintaining ethical behavior. If a person wants to show a stable moral behavior, he must maintain a high identity of their own moral standards in different situations ${ }^{[24]}$. Therefore, employees with high moral identity often have higher moral judgment ability. They can distinguish between ethical behavior and unethical behavior. This also stems from their willingness to maintain the moral self-concept, that is, employees with high moral identity should be consistent with their moral perceptions to avoid self-dissonance ${ }^{[22]}$. This study believes that the influence of instrumentalism ethical climate on unethical behavior is moderated by the level of employees' own moral identity. For employees with higher moral identities, the more they attach importance to their moral identity, he stronger their ability to process moral information, the higher the ability to make moral judgments $[25,26]$. So they are not easy to be assimilated by self-interest of external circumstances, nor is the ethical behavior to be activated. From another point of view, when employees' moral identity is low, their sensitivity to moral information is low, and their moral judgment ability is poor. So they are easily assimilated by external self-interest situations and generate unethical behavior. Based on the above analysis, we hypothesize the following:

Hypothesis 3a: Employee moral identity moderates the strength of the relationship between instrumentalism ethical climate and unethical behavior. Such that the relationship is stronger (weaker) when employee moral identity is low (high).

Based on Hypothesis 2 and Hypothesis 3a, this study proposes a moderated-mediation model: moral identity moderate the mediating role of instrumentalism ethical climate. In other words, the indirect relationship between supervisor BLM and unethical behavior through the intermediary role of instrumentalism ethical climate depends on the moral identity. Specifically, the lower the moral identity, the stronger the indirect relationship between supervisor BLM and unethical behavior via instrumentalism ethical climate. On the contrary, the influence of the supervisor BLM on unethical behavior via instrumentalism ethical climate will be reduced when the level of employee moral recognition is high. Based on this analysis, we specifically hypothesize:

Hypothesis 3b: Employee moral identity moderates the strength of the indirect relationship between supervisor BLM and unethical behavior via instrumentalism ethical climate. Such that the mediated relationship is stronger (weaker) when employee moral identity is low (high).

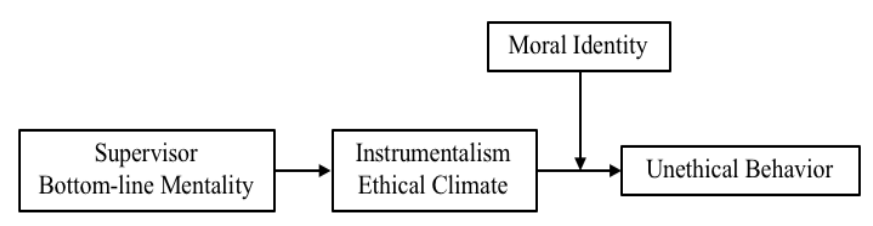

Fig. 1. Hypothesized theoretical model

\section{MethOD}

\section{A. Sample and Procedure}

The data of this study was collected in the form of questionnaires and through the investigation of the departments or teams of several enterprises in Zhejiang Province. The number of employees in each department or team was not less than 3 , and the questionnaires were distributed using the method of pairing supervisors and subordinates. To avoid common method deviations, we collected data from supervisor and employees, respectively. The items about supervisor BLM, instrumentalism ethical climate and moral identity are filled by employees, and items of unethical behavior are filled by supervisors.

A total of 80 sets of questionnaires were distributed, including 80 questionnaires for supervisors and 400 questionnaires for employees. We received responses from 75 supervisors and 373 employees. After matching data, we had usable data from 67 supervisors and 319 employees, for an overall response rate of $80.4 \%$. Among them, there are 184 men (55.7\%) and 135 women (42.3\%); the age is mainly 2130 years old (49.2\%); the education level is mainly junior high school and below (59.2\%); the working age is 2-5 The main year is (48.9\%); the income level is mainly $3000-4000$ yuan (57.7\%).

\section{B. Measure}

This study measures the four variables including supervisor BLM, instrumentalism ethical climate, unethical behavior, and moral identity. It mainly refers to the more mature scales from foreign scholars and also listens to suggestions from relevant professors. First, the questionnaire was pre-investigated and the questionnaire was revised according to the pre-research results to ensure the reliability and validity of the scale. 
1) Supervisor bottom-line mentality. Supervisor bottomline mentality was assessed by the employees with four items from Greenbaum et al.'s scale ${ }^{[11]}$. Sample items include "supervisor only cares about the business," and "supervisor cares more about profits than employee well-being." Responses for these items were made on a 5-point response scale from $1=$ strongly disagree to $5=$ strongly agree $(\alpha=.85)$.

2) Instrumentalism ethical climate. Instrumentalism ethical climate was assessed by the employees with seven items from Victor and Cullen's scale ${ }^{[16]}$. Sample items include "In this company, people protect their own interests above all else," and "There is no room for one's own personal morals or ethics in this company." Responses for these items were made on a 5-point response scale from $1=$ strongly disagree to $5=$ strongly agree $(\alpha=.72)$.

3) Unethical behavior. Unethical behavior was assessed by the supervisors with seven items from Moore et al.'s scale ${ }^{[2]}$. Sample items include "Falsifying a receipt to get reimbursed for more money than he or she spent on business expenses," and "Discussing confidential company information with an unauthorized person." Responses for these items were made on a 5 -point response scale from $1=$ never to $5=$ very often $(\alpha=.92)$.

4) Moral identity. Moral identity was assessed by the employees with ten items from Aquino and Reed's scale ${ }^{[22]}$. The scale first lists a set of characteristics that individuals may have (such as kindness, friendly, etc.). Then the respondent imagines what it feels like to be such a person. Finally, the respondent evaluates 10 items. For example, "Being a person with these qualities will make me feel good," and "These quality characteristics are very important parts and contents of my personal characteristics.” Responses for these items were made on a 5 -point response scale from $1=$ strongly disagree to $5=$ strongly agree $(\alpha=.74)$.

\section{ResULts}

\section{A. Common Method Bias}

This study draws on Edwards and Lambert's test method for common method bias ${ }^{[27]}$. First, Harman's single factor test technique is used to perform relevant statistical tests. The specific approach is to put all items of the questionnaire used in this study into the exploratory factor analysis, test the factor analysis without rotation, the principal component analysis method extracts six common factors, and obtain the load of the first principal component. The amount is $22.702 \%$, which does not reach the establishment standard of $40 \%$. Therefore, there is no single source bias among the variables in the study.

\section{B. Descriptive Statistics}

This study performed descriptive statistical analysis of the variables. The results are shown in Table 1 . We can see that the supervisor BLM $(r=.27, p<.001)$ and the instrumentalism ethical climate $(r=.32 \quad p<.001)$ are positively related to unethical behavior, respectively. Moreover, the supervisor BLM $(r=.59, p<.001)$ is positively related to the instrumentalism ethical climate. These results provide initial support for subsequent hypothesis testing.

TABLE I. DESCRIPTIVE ST ATISTICS AND STUDY VARIABLE INTERCORRELATION

\begin{tabular}{|c|c|c|c|c|c|c|c|c|c|c|}
\hline Variable & $M$ & $S D$ & 1 & 2 & 3 & 4 & 5 & 6 & 7 & 8 \\
\hline 1. Sex & - & - & & & & & & & & \\
\hline 2. Age & 2.69 & .98 & -.06 & & & & & & & \\
\hline 3. Education & 1.56 & .78 & -.05 & -.04 & & & & & & \\
\hline $\begin{array}{l}\text { 4. organizational } \\
\text { tenure }\end{array}$ & 2.50 & 1.37 & $-.20 * * *$ & $.43 * * *$ & $.19 * * *$ & & & & & \\
\hline 5.Income & 2.50 & .72 & $-.17 * *$ & .08 & $.23 * * *$ & $.29 * * *$ & & & & \\
\hline 6. Supervis or BLM & 2.90 & .94 & .03 & .01 & -.06 & .02 & -.06 & & & \\
\hline $\begin{array}{l}\text { 7. Instrumentalism } \\
\text { ethical climate }\end{array}$ & 2.71 & .65 & .01 & -.06 & .01 & .04 & -.07 & $.59^{* *}$ & & \\
\hline 8.Unethical behavior & 1.31 & .62 & $-.12^{*}$ & .05 & $-.13^{*}$ & -.06 & -.08 & $.27 * * *$ & $.32 * * *$ & \\
\hline 9. Moral identity & 3.14 & .58 & $.15^{* *}$ & $-.18^{* * *}$ & $-.20 * * *$ & .01 & $\begin{array}{c}.28^{* *} \\
*\end{array}$ & -.06 & -.08 & $\begin{array}{c}- \\
.27 * * *\end{array}$ \\
\hline
\end{tabular}

\section{Tests of Hypotheses}

According to Baron and Kenny's mediating test procedure

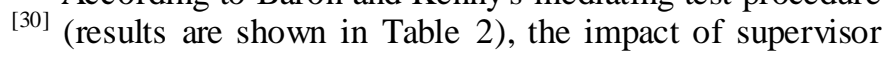
BLM on the instrumentalism ethical climate $(\beta=.40, p<.001)$ is first examined, so hypothesis 1 was verified. Secondly, instrumentalism ethical climate is positive related to unethical behavior $(\beta=.25, p<.001)$, but the relationship between supervisor BLM to unethical behavior was not significant after adding the mediation variable. This shows that the instrumentalism ethical climate plays a complete intermediary role between the supervisor BLM and unethical behavior. Hypothesis 2 is verified. Finally, in order to support Hypothesis 3a, the instrumentalism ethical climate and moral identity are treated as centralization and the product terms of the two are calculated, and the dependent variable is used as a regression analysis of the independent variable, the adjusted variable, and the product term. The interaction is negative related to unethical behavior $(\beta=-.10, \mathrm{p}<.001)$, so hypothesis $3 a$ is verified.

In order to further explain the moderation of the moral identity, a simple slope analysis was performed and the results are shown in Figure 2. It can be seen that when employees' moral identity is low, the instrumentalism ethical climate has a significant impact on unethical behavior $(\beta=.59, p<.05)$. When the level of employee moral identity is high, the instrumentalism ethical climate has no significant effect on unethical behavior $(\beta=-.24, p>.05)$. 


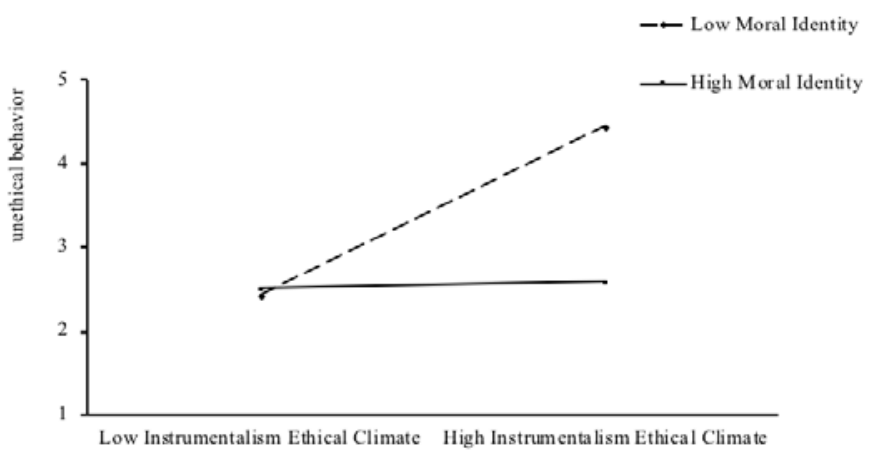

Fig. 2. The moderation of moral identity

TABLE II. REGRESSION RESULT FOR OVERALL MODEL

\begin{tabular}{|c|c|c|c|c|c|c|c|c|c|}
\hline \multirow{2}{*}{ Variable } & \multicolumn{3}{|c|}{ Instrumentalism ethical climate } & \multicolumn{6}{|c|}{ Unethical behavior } \\
\hline & M11 & M12 & M13 & M21 & M22 & M23 & M24 & M25 & M26 \\
\hline Sex & .02 & .01 & -.16 & $-.14 *$ & -.14 & -.08 & -.14 & -.08 & -.03 \\
\hline Age & -.10 & -.09 & -.08 & .09 & .09 & .04 & .12 & .06 & .03 \\
\hline Organizational tenure & .13 & .10 & .10 & -.08 & -.10 & -.09 & -.12 & -.11 & -.10 \\
\hline Income & -.09 & -.05 & -.08 & -.06 & -.04 & .04 & -.03 & .06 & .09 \\
\hline Education & -.01 & .02 & .01 & -.09 & -.08 & -.04 & -.08 & -.04 & -.05 \\
\hline Supervis or BLM & & $.59 * * *$ & $.59 * * *$ & & $.27 * * *$ & $.26 * * *$ & .12 & .09 & .07 \\
\hline Moral identity & & & $.09 *$ & & & & $.24 * * *$ & $.27 * * *$ & $-.21^{* *}$ \\
\hline$M \times W$ & & & & & & & & $-.30 * * *$ & $-.35^{* * *}$ \\
\hline $\begin{array}{l}\text { Instrumentalism ethical } \\
\text { climate }\end{array}$ & & & & & & $-.28 * * *$ & & . & $31 * * *$ \\
\hline$R^{2}$ & .02 & .36 & .37 & .04 & .11 & .17 & .15 & .22 & .31 \\
\hline$\Delta R^{2}$ & .02 & $.35 * * *$ & $.01^{*}$ & $.04 *$ & $.07 * * *$ & $.06 * * *$ & $.04 * * *$ & $.07 * * *$ & $.08 * * *$ \\
\hline$F$ & 1.22 & $29.80 * * *$ & $26.13 * * *$ & $2.57^{*}$ & $6.44 * * *$ & $9.31 * * *$ & $7.72 * * *$ & $11.03 * * *$ & $15.05 * * *$ \\
\hline
\end{tabular}

To support the hypothesis $3 \mathrm{~b}$, that is, moderated-mediation model. This study used Preacher, Rucker, and Hayes's conditional indirect effect test program ${ }^{[29]}$. As can be seen from Table 3, when employee' moral identity is low, the confidence intervals of the $95 \%$ level of the indirect effect of the supervisor BLM on unethical behavior are $[.03, .12]$ and $[.10, .24]$, respectively.
Thus, the indirect effect is significant. It is indicated that when the moral identity is low, the supervisor BLM has a higher influence on unethical behavior through the instrumentalism ethical climate. On the contrary, when the moral identity level is high, the mediating role of the instrumentalism ethical climate is low. Hypothesis $3 \mathrm{~b}$ is verified.

TABLE III. MORAL IDENTITY: CONDITION INDIRECT EFFECTS

\begin{tabular}{cccccc}
\hline & Indirect effect & SE & Z & \multicolumn{2}{c}{$95 \%$ Confidence Intervals } \\
\hline M-SD & .17 & .03 & $5.90^{* * *}$ & .10 & .24 \\
M & .07 & .02 & $3.12^{* *}$ & .03 & .12 \\
M+SD & -.02 & .03 & -.61 & -.07 & .03 \\
\hline
\end{tabular}

\section{DISCUSSION}

Based on social information processing theory, this study is adopted to introduce the supervisor BLM into the study of the antecedent variables of unethical behavior from a new theoretical perspective. We explain how the supervisor BLM leads to the instrumentalism ethical climate in the organization, thereby leads to unethical behaviors among employees. In addition, we examine the role of moral identity in strengthening or reducing this relationship to explain when the supervisor BLM will influence the unethical behavior via instrumentalism ethical climate. This contributes to the further improvement of the theoretical framework of unethical behavior.
All the hypotheses of this study are supported. The main conclusions are as follows: (1) Supervisor BLM is positively related to instrumentalism ethical climate, and instrumentalism ethical climate mediates the relationship between supervisor BLM and employee unethical behavior. This conclusion shows that supervisor BLM will create a negative ethical climate, reduce moral standards, and maybe encourage employees to become selfish, thus resulting in unethical behavior. (2) Employee moral identity negatively moderates the relationship between instrumentalism ethical climate and employee unethical behavior. When the level of employee moral identity is low, it strengthens the mediating role of instrumentalism ethical climate. If employees have low moral identity, they couldn't be ability to judge whether the 
behavior is right or not. Moreover, employees may not keep his moral bottom-line, and they may be vulnerable to the negative ethical climate to promote the emergence of unethical behavior.

\section{A. Implications for Theory}

First, the study has enriched the research on supervisor BLM, and promoted the localization process of the research on supervisor BLM. Reviewing previous literature, there are still fewer studies on supervisor BLM, and most of them are foreign studies ${ }^{[11]}$, which have not been studied in the context of China. This is of great significance to broaden the theoretical research of supervisor BLM and to enrich the cross-cultural research of supervisor BLM. Second, in order to reveal the "Black box" of the supervisor BLM and unethical behavior, starting from social information processing theory, this study demonstrates that the employees through the supervisors pay attention to the bottom-line results of information processing, inspired from the situation, increase the likelihood of the exercise of ethical behavior. Third, this article clarifies that moral identity is negatively moderate the relationship between instrumentalism ethical climate and unethical behavior. This shows when employee moral identity is low, it will enhance the positive influence of instrumentalism ethical climate on unethical behavior, and further propose the moderated-mediation model to explore the moderating effect of moral identity in the entire model.

\section{B. Implications for Practice}

First, organizations should recognize that supervisor's behavior and attitude have important role models for their subordinates. Subordinates usually process the information sent by the supervisor, and the result of the information processing will be used as a guide for future behavior in the organization. While supervisor BLM may seem to be beneficial for gaining the desired outcome of the organization (such as maximizing profits), it may also be abnormal. Supervisors should emphasize appropriate actions to achieve the necessary bottom line expectations. This is a responsible management approach. Second, the organization should also realize that the consequences of the employees' unethical behavior are serious and that they have to pay a very heavy price for the organization. Although the bottom line results are very important, they must also be given full attention. Therefore, the organization can employ supervisors who can strengthen ethical compliance (such as ethical leadership) and work hard to achieve bottom line results to avoid the formation of negative ethical climate of the organization and reduce the negative behavior of employees.

\section{Limitations and Future Directions}

Based on the theory of social information processing, this study verifies the relationship between supervisor BLM and employee ethical behavior. Some meaningful conclusions have been obtained, but there are still limitations. The future still needs further research and discussion. First, the data of this study are cross-sectional data, so we cannot clearly determine the direction of causality between variables. We can only use past research to guess that supervisor behavior and attitude may become a demonstration of employee behavior and thus determine its causal direction. Future research can use multiple time points to collect sample data, and this direction of causality has been clarified. Second, the relationship between supervisor BLM and instrumentalism ethical climate is not unique. This article is based on the assumption that supervisor behavior will affect employee behavior, but it does not rule out that employees are not affected by the leadership. Therefore, in the future research, researchers can further study the intermediation mechanism and improve the theoretical framework. Third, the scale of supervisor BLM is developed in the western context. Although the reliability and validity of the scale itself is good, there will be differences in the understanding of the bottom line in different cultural contexts. Therefore, attempting to develop a localization scale is meaningful to the future research.

\section{REFERENCES}

[1] Kish-Gephart J J, Harrison D A, Treviño L K. Bad apples, bad cases, and bad barrels: meta-analytic evidence about sources of unethical decisions at work [J]. Journal of Applied Psychology, 2010, 95(1):1-31.

[2] Moore C, Detert J R, Treviño L K, et al. why employees do bad things: moral disengagement and unethical organizational behavior [J]. Personnel Psychology, 2012, 65(1):1-48.

[3] Baucus, M. S., Baucus, D. A. Paying the Piper: An Empirical Examination of Longer-Term Financial Consequences of Illegal [J]. The Academy of Management Journal, 1997,40(1):129-151

[4] Gunthorpe, D. L. A Quantitative Analysis of the Impact of an ethical Behavior: By Publicly Traded Corporations [J]. Journal of Business Ethics, 1997,16(5):537-543

[5] Sullivan, B. N., Haunschild, P., Page, K. Organizations Non Gratae? The Impact of Unethical Corporate Acts on Inter-organizational Networks [J]. Organization Science, 2007,18(1):55-70

[6] Hill, J. A., Eckerd, S., Wilson, D., et al. The Effect of Unethical Behavior on Trust in a Buyer-Supplier Relationship: The Mediating Role of Psychological Contract Violation [J]. Journal of Operations Management, 2009,27(4):281-293

[7] Bono J. E, Ilies R. Charisma, Positive Emotions and Mood Contagion [J]. The Leadership Quarterly, 2006, 17( 4) : 317 -334.

[8] Kalshoven K, Dijk H V, Boon C. Why and when does ethical leadership evoke unethical follower behavior? [J]. Academy of Management Annual Meeting Proceedings, 2016, 2013(1):13515-13515.

[9] Effelsberg D, Solga M. Transformational Leaders’ In-Group versus OutGroup Orientation: Testing the Link Between Leaders' Organizational Identification, their Willingness to Engage in Unethical ProOrganizational Behavior, and Follower-Perceived Transformational Leadership [J]. Journal of Business Ethics, 2015, 126(4):581-590.

[10] Wolfe D M. Is there integrity in the bottom line: Managing obstacles to executive integrity [J]. 1988.

[11] Greenbaum R L, Mawritz M B, Eissa G. Bottom-line mentality as an antecedent of social undermining and the moderating roles of core selfevaluations and conscientiousness [J]. Journal of Applied Psychology, 2012, 97(2):343.

[12] Salancik G R, Pfeffer J. A social in formation processing approach to job attitudes and task design [J]. Adm Sci Q, 1978, 23(2):224-253.

[13] Kuntz, J. R C, Kuntz, et al. Characterizing Ethical Cases: A CrossCultural Investigation of; Individual Differences, Organizational Climate, and Leadership on; Ethical Decision-Making [J]. Journal of Business Ethics, 2013, 113(2):317-331. 
[14] Treviño L K, Brown M, Hartman L P. A qualitative investigation of perceived executive ethical leadership: Perceptions from inside and outside the executive suite [J]. Human Relations, 2003, 56(1):5-37.

[15] Pringle C D, Longenecker J G. The Ethics of MBO [J]. Academy of Management Review, 1982, 7(2):305-312.

[16] Victor B, Cullen J B. The organizational bases of ethical work climates [J]. Administrative Science Quarterly, 1988, 33(1):101-125.

[17] Martin K D, Cullen J B. Continuities and Extensions of Ethical Climate Theory: A Meta-Analytic Review [J]. Journal of Business Ethics, 2006, 69(2):175-194.

[18] Berscheid E, Graziano W. Outcome dependency: Attention, attribution, and attraction [J]. Journal of Personality \& Social Psychology, 1976, 34(34):978-989.

[19] Brown M E, Treviño L K, Harrison D A. Ethical leadership: A social learning perspective for construct development and testing [J]. Organizational Behavior \& Human Decision Processes, 2005, 97(2):117-134

[20] Treviño L K, den Nieuwenboer N A, KishGephart JJ. (Un)ethical behavior in organizations [J]. Annual Review of Psychology, 2014, 65(1):635.

[21] Blasi A. Moral cognition and moral action: A theoretical perspective [J]. Developmental Review, 1983, 3(2):178-210.

[22] Aquino K, Reed Ii A. The self-importance of moral identity [J]. Journal of Personality \& Social Psychology, 2002, 83(6):1423.
[23] Mulder L B, Aquino K. The role of moral identity in the aftermath of dishonesty [J]. Organizational Behavior \& Human Decision Processes, 2013, 121(2):219-230.

[24] Wang Xingchao, Yang Jiping. Moral Escape and College Students Prosocial Behavior: The Moderating Effect of Moral Identity [J]. Psychological Science, 2013(4):904-909. In Chinese.

[25] Aquino K, Freeman D, Reed Ii A, et al. Testing a social-cognitive model of moral behavior: The interactive influence of situations and moral identity centrality [J]. Journal of Personality \& Social Psychology, 2009, 97(1):123.

[26] Zhang Fawang, Liao Jianqiao. Ethical Leadership and Ethics Report: Role of Moral Efficacy and Moral Identity [J]. Management Review, 2017, 29(12):94-105. In Chinese

[27] Edwards J R, Lambert L S. Methods for integrating moderation and mediation: a general analytical framework using moderated path analysis[J]. Psychological Methods, 2007, 12(1):1.

[28] Baron, R. M., \& Kenny, D. A. The moderator-mediator variable distinction in social psychological research: conceptual, strategic, and statistical considerations [J] Journal of Personality and Social Psychology, 1986, 51(6):1173-1182.

[29] Kristopher J. Preacher, Derek D. Rucker, Andrew F. Hayes. Addressing Moderated Mediation Hypotheses: Theory, Methods, and Prescriptions. [J]. Multivariate Behav Res, 2007, 42(1):185-227 